\title{
Genetic diversity of Plantago major L. local populations in the habitats of Nizhniy Tagil different in the level of technogenic load
}

\author{
E. Artemenko*, E. Zhuikova, I. Kiseleva \\ Ural Federal University, Yekaterinburg, Russia \\ *e-mail: lisaaartemenko@gmail.com
}

Key words: Plantago major, genetic diversity, ISSR-analisis

Motivation and Aim: It has been shown that different types of pollutants can affecton genetic diversity of populations. Technogenic load can lead to changes in frequency of mutations, direction of selection of genotypes and/or genetic drift as a result of elimination of a large number of non-adapted individuals [1]. The aim is to study the level of genetic diversity of local populations of Plantago major growing in 5 location of Nizhny Tagil, differing in the level of technogenic load.

Methods and Algorithms: NA was isolated by the method of S. Porebski [2] with some modifications. Nine UBC primers was used for PCR. Visualization of PCR results was carried out by horizontal electrophoresis on a $1.2 \%$ agarose gel in addition of ethidium bromide in $1 \times \mathrm{TBE}$ buffer. The result of all electrophoregrams were processed by the Image J program. The presence and absence matrices for each primer were processed in PAST [3] and JeneAlex [4] program.

Results: 52 samples of $P$. major were analyzedin the study; standardization of the ISSR protocol, quantitative and qualitative assessments of the NAwere done; the maximum, minimum and average number of bands per sample, habitat and primer, as well as indicators of genetic diversity: the percentage of polymorphic loci, effective alleles, expected heterozygosity, the Shannon's information index, the genetic distance and identity of Nei, the percentage of molecular variance within and among populations.

Conclusion: Genetic analysis of $P$. major subpopulations indicates that local populations in contaminated technogenic are less diverse genetically than population of background areas. Since genetic diversity is lower among plants in contaminated areas, despite their potentially higher level of mutational variability, the mutagenic effects of pollutants may not be the driving force behind the formation of genetic differences found between different populations.

\section{References}

1. Bae Ch.-H., Ryu J. (2012) Genetic diversity and relationship analysis of genus Taraxacum accessions collected in Korea. Korean J. Plant Res. 25(3):329-338.

2. Porebski S., Bailey L.G., Baum B.R. (1997) Modification of a CTAB DNA extraction protocol for plants containing high polysaccharides and polyphenol component. Plant Molecular Biology Reporter. 15:8-15.

3. Hammer O., Harper D.A.T., Ryan P.D. (2001) PAST: Paleontological statistics software package for education and data analysis. Palaeontologia Electronica. 4(1):9.

4. Peakall R., Smouse P.E. (2012) GenAlEx 6.5: genetic analysis in Excel. Population genetic software for teaching and research-an update. Bioinformatics. 28:2537-2539. 